\title{
Gross Anatomical Studies on the Cervical Vertebrae of Emu (Dromaius novaehollandiae)
}

\author{
P. Sridevi*, K. Rajalakshmi and M. Sivakumar \\ Department of Veterinary Anatomy and Histology, Rajiv Gandhi Institute of Veterinary \\ Education and Research, Kurumbapet, Puducherry-605010, India \\ *Corresponding author
}

\section{Keywords}

Cervical vertebrae, Styloid Processes,

Foramen

Transversarium,

Emu.

Article Info

Accepted:

18 July 2019

Available Online:

10 August 2019

\section{A B S T R A C T}

The present study was conducted on the cervical vertebrae of three adult emu birds. The vertebrae were 17 in number. The atlas was ring shaped, the body of the axis presented anteriorly, a triangular dens and short thick transverse processes laterally and whose root presented a large foramen transversarium. There was a gradual increase in the length of the body of cervical vertebrae from third to seventeenth. The anterior end of the bodies showed a transversely concave and dorso-ventrally convex articular surface, while the posterior end showed a reverse condition. The root of the transverse process except the atlas presented the foramen transversarium.The styloid processes were observed as bony spicules whose pointed free ends gradually reached the level of the posterior articular process. The dorsal spinous process was in the form of a small tubercle in the 3rd cervical vertebra which gradually increased in length towards the caudalof the series. The ventral spinous process was absent from 3rd to 17 th cervical vertebrae. The cranial and caudal vertebral notches on the pedicel of the adjacent cervical vertebrae enclosed intervertebral foramen.

\section{Introduction}

The number of cervical vertebrae varied with the length of the neck and provided increased flexibility to the neck region thereby enabling many birds with immobile eyes to rotate their head and to focus on objects which are close to or far away. The highly flexible neck facilitated by the saddle shaped articular surface of the bodies, plays an important role in pruning and eye sight. The great degree of movement exhibited by the atlanto- occipital joint enables the beak to perform wide varieties of tasks. The present study on the gross morphological features of the cervical vertebrae of emu was undertaken due to the paucity of studies in this regard.

\section{Materials and Methods}

The materials for the study were collected from three adult emu birds of either sex brought for post mortem examination to the Department of Veterinary Pathology, Rajiv 
Gandhi Institute of Veterinary Education and Research, Puducherry, India. The cervical vertebrae was collected by the regular process of maceration, cleaned, dried and the various gross anatomical features were recorded.

\section{Results and Discussion}

The cervical vertebrae were 17 (Fig 1) in number in emu, similar to the domestic birds as reported by Nickel et al., (1977) and Pawan kumar and Gurdial Singh (2014) in emu. However, Nickel et al., 1977 reportedthe presence of 14 cervical vertebrae in fowl and duck, 17 in goose and 12 in the pigeon and Mc lelland (1990) reported 16 cervical vertebrae in the adult chicken.

Atlas was narrow and ring shaped(Fig 2) and had a dorsal and ventral arch which concurs with the findings of Nickel et al., 1977 in domestic birds and Mc lelland (1990) in adult chicken. The atlas lacked a vertebral body which coincides with the findings of Nickel $e t$ al., 1977in domestic birds.

The dorsal arch (Fig 3)of atlas was thin delicate and had a small notch about the middle of its anterior border. The posterior border of the dorsal archarticulated laterally with the anterior articular process of the axis and presented a transverse notch between. Behind this articulation, the arch presented a short blunt caudo-laterally directed process on either side. The ventral arch (Fig 3) presented anteriorly a deep articular socket for the single occipital condyle. The articular facet extended dorsally and presented a depression for the odontoid process of axis similar to the observations of Pawan kumar and Gurdial Singh(2014) in emu and Nickel et al., 1977 in domestic birds. Posteriorly the ventral arch presented a slightly concave articular area which articulated with the anterior articular area on the body of axis
The body of the axis presented anteriorly a triangular dens (Fig 4)similar findings were noticed in emu by Pawan kumar and Gurdial Singh (2014). It had a flat dorsal surface while the ventral surface showed a hemispherical articular facet. The dens articulated with the occipital condyle which concurs with finding of Nickel et al., 1977 in domestic birds. Below the dens was the crescentic anterior articular area which articulated with the posterior part of ventral arch of atlas.

The dorsal spinous process (Fig 5) was in the form of a thick ridge which was pointed and narrow anteriorly and broader and blunt posteriorly. It presented a foramen at its root. The ventral spinous process (Fig 5) was a seen in the form of a raised ridge along the posterior third of axis. A similar ventral spinous process was reported by Pawan kumar and Gurdial Singh (2014) in emu. The anterior articular process was seen in the form of a small oval facet while the posterior process was a large, oval and slightly concave facet directed downwards with a tubercle present on its dorsal aspect. In front of the posterior articular facet was a large foramen. Between the anterior and posterior articular process was a short thick transverse process whose root presented a large foramen transversarium (Fig 6)with anterior and posterior openings in contrast to the absence of transverse process in domestic birds as reported by Nickel et al., 1977. The posterior extremity of the body had a spherical fovea and the dorsal surface of the body was concave transversely

There was a gradual increase in the length and width of the body of cervical vertebrae from 3rd to 17 th. The anterior extremity of the bodies were concave from side to side and convex from above downward while the posterior extremity were in reverse condition which is in agreement with the finding made 
by Nickel et al., 1977 in domestic birds. The anterior articular process of3rd and 4th cervical vertebrae were oval, convex placed dorso-laterally and was directed downward. The anterior margin of all cervical vertebrae of the horizontal lamina were "V" shaped. The anterior articular process of the 5th cervical vertebra was directed downward and forward but from 6th onwards they were placed dorso-medially. The anterior articular processes of 5th to 9th were similar in size. From 10thonwards the size of the anterior articular process increased gradually. The anterior margin of the horizontal lamina of all cervical vertebrae was "V" shaped. The posterior articular process of 3rd and 4thwere large oval and slightly concave and were separated by a shallow wide notch. The posterior articular process from 5th cervical vertebrae was separated by a deep notch. Posterior articular process of 6th, 7th' and 8th cervical vertebrae were large in size, whereas its size increased gradually from 9thonwards. The dorsal spinous process was in the form of a small tubercle in the 3rd cervical vertebrae which gradually increased in length in the caudal of the series. The dorsal spinous process was thick plate like with a rough dorsal border and presented a fossa on its cranial and caudal ends. The cranial fossa (Fig.7) became deeper, wider and the caudal fossa became deeper and formed an inverted V shape. A concave depression was observed on either side of the dorsal spinous process in 3rd, 4th, 5th cervical vertebrae, which was a blind foramen in the 6th cervical vertebrae, patent in the 7 th, double in the 8 th, single large in 9th and 10th, narrowed in 11th and 12 th, wider and deeper from 13th onwards. A faint oblique ridge which connected the anterior and posterior articular process was observed on the 3rdand 4th cervical vertebrae. The faint ridge was replaced by a groove from 5 th cervical vertebrae onwards and it gradually widened in the caudal of the series, in agreement with the finding recorded by Pawan kumar and Gurdial Singh (2014) in emu. The styloid processes (Fig 8)were observed as bony spicules whose pointed free ends gradually reached the level of the posterior articular process as recorded by Pawan kumar and Gurdial Singh (2014) in emu. The bony spicules increased in thickness from slender, sharp pointed ends to short stumpy ends. The transverse processes of the 17 th cervical vertebrae were very thick.

\section{Table.1}

Fig : 1. Lateral view cervical vertebrae of Emu

1. First cervical 2. Second cervical 3.

Third cervical 4. Fourth cervical 5.

Fifth cervical 6. Sixth cervical 7.

Seventh cervical 8. Eighth cervical 9.

Ninth cervical 10. Tenth cervical 11.

Eleven cervical 12. Twelve cervical 13.

Thirteen cervical 14. Fourteen

cervical 15. Fifteen cervical 16. Sixteen

cervical 17. Serenteen cervical

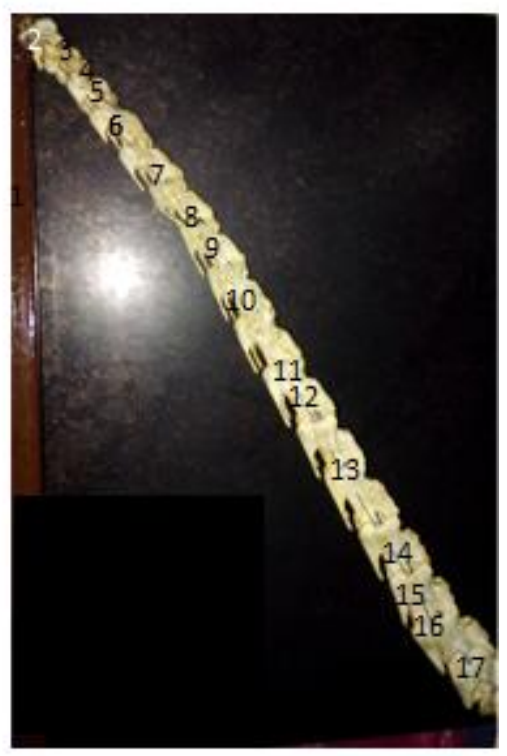


Fig : 2.Anterior view of Atlas of Emu

1. Dorsal arch

2. Ventral arch

3. Articular socket for occipital condyle

4. Vertebral foramen

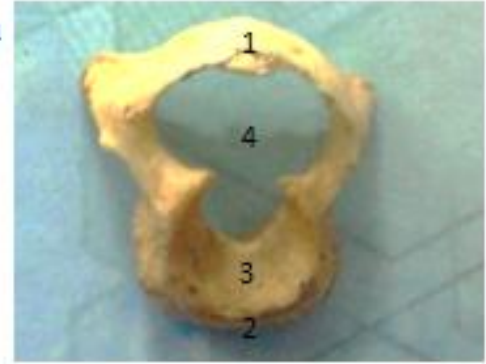

Fig : 3. Posterior view of Atlas of Emu

1. Dorsal arch

2. Ventral arch

3. Facet for anterior articular process of axis

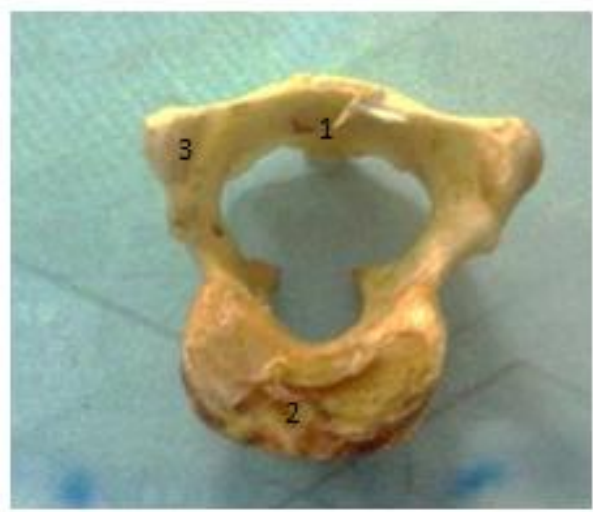

Fig : 5. Lateral view Axis of Emu

1. Ventral arch of atlas

2. Dorsal spinous process

3. Posterior articular process

4. Ventral spinous process

5. Body of axis

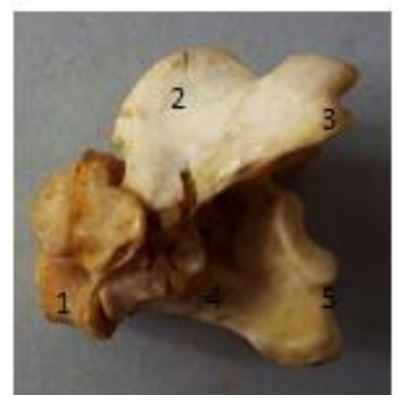

Fig : 4.Anterior view Axis of Emu

1. Dens

2. Dorsal spinous process

3. Foramen transversarium

4. Transverese process

5. Anterior articular process

6. Posterior articular process

7. Vertebral foramen

8. Anterior articular area

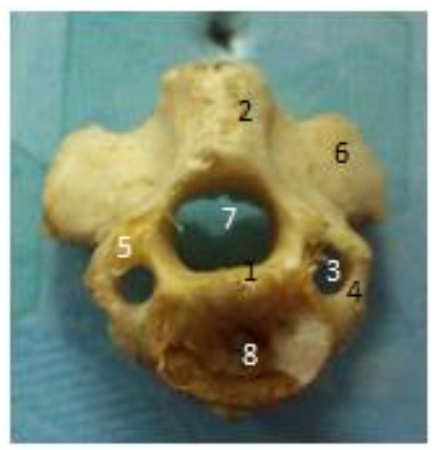


Fig : 6. Caudal view Axis of Emu

1. Body

2. Dorsal spinous process

3. Foramen transversarium

4. Transverses process

5. Posterior articular process

6. Vertebral foramen

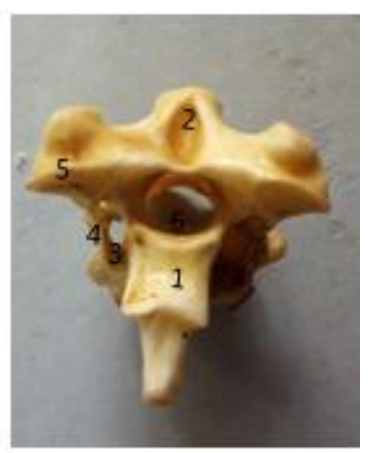

Fig : 7. Dorsal view cervical vertebrae of Emu

1. Dorsal spinous process of Third Cervical vertebrae

2. Inverted $\mathbf{v}$ shape fossa

3. Anterior articular process

4. Posterior articular process

5. Styloid process

6. Foramen transversarium

7. Cranial fossa

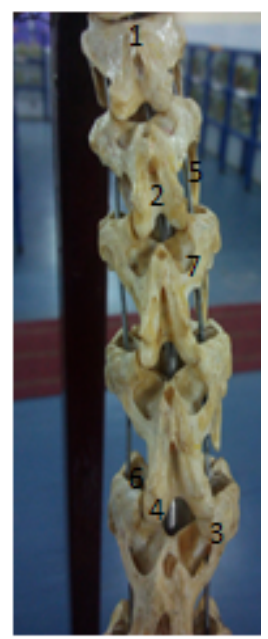

Fig : 8. Dorsal view cervical vertebrae of Emu

1. Anterior articular process

2. Posterior articular process

3. Styloid process

4. Foramen transversarium

5. Cranial fossa

6. Transverse process

7. Canalis transversarius



The root of the transverse process from the 3rd cervical vertebrae onwards presented a foramen transversarium, the aggregate of which enclosed the canalis transversarium (Fig 8) which carried the vertebral artery and vein and a branch of sympathetic nerve. Which is in agreement with the finding made by Pawan kumar and Gurdial Singh (2014) in emu and Nickel et al., 1977 in domestic birds. The ventral spinous process was absent from 3 rd to 17 th cervical vertebrae. The ventral surface of the bodies of cervical vertebrae presented a paired ventral crest which was widely separated in the cranial series, but 
converged gradually, enclosing a groove which deepened, until the 16th cervical vertebrae. In the last cervical vertebrae, the paired ventral crest got completely separated from the base of the transverse process and was found close together as reported by Nickel et al., 1977, in domestic birds. Nickel et al., 1977 had observed a paired cristae verntrales which may also become fused into a single ridge. The bodies of the cervical vertebrae presented along their ventral surface a constriction about the middle until the 15 th cervical vertebrae, but it was not so in the last two. The cranial and caudal vertebral notches of adjacent cervical vertebrae contributed to the formation of intervertebral foramen, which concurs with the findings made by Pawan kumar and Gurdial Singh (2014) in emu and Nickel et al., 1977 in domestic birds. Richard (2011) described the presence of haemal canal in the cervical vertebrae of pelican and reported that this was intended for the protection of carotid arteries.

\section{Acknowledgement}

Authors are thankful to the Dean,Rajiv Gandhi Institute of Veterinary Education and Research,Puducherryfor providing the basic infrastructure for carrying out this research work

\section{References}

Nickel, R., Schummer, A. and Seiferle, E. (1977). Anatomy of the domestic birds. 2 nd ed., Verlag Paul Parey, Berlin, Hamburg. pp: 16-17.

Richard, O. 2011- On the anatomy of vertebrates vol 2.39-42-p

Kumar, Pawan and Singh Gurdial. 2014. Gross anatomy of Axial skeleton in emu (Dromaius novaehollandiae). Indian Journal of Veterinary Anatomy26: 8791

Mc Lelland, J. (1990). A Colour Atlas of Avian Anatomy. Wolfe Publishing Ltd, England. pp: $42-43$

\section{How to cite this article:}

Sridevi, P., K. Rajalakshmi and Sivakumar, M. 2019. Gross Anatomical Studies on the Cervical Vertebrae of Emu (Dromaius novaehollandiae). Int.J.Curr.Microbiol.App.Sci. 8(08): 2271-2276. doi: https://doi.org/10.20546/ijcmas.2019.808.263 